Accepted for publication in Journal of Workplace Learning on 14/05/2015.

Measuring team learning behaviours through observing verbal team interaction.

\author{
Elisabeth Raes ${ }^{1}$, Anne Boon ${ }^{1}$, Eva Kyndt ${ }^{1}$, Filip Dochy ${ }^{1}$ \\ ${ }^{1}$ Centre for Research on Professional Learning \& Development, and Lifelong Learning, \\ University of Leuven, Belgium
}

\title{
Correspondening author:
}

Elisabeth Raes, Centre for research on Professional Learning \& Development, and Lifelong Learning, University of Leuven, Dekenstraat 2 PB 3772, Leuven 3000, Belgium Email: elisabeth.raes@ppw.kuleuven.be. 


\section{Structured abstract}

Purpose: Over time, team learning in an organisational context has been investigated more and more. In these studies, there is a dominant focus on team members' perception of team learning behaviours. As an answer to the observed lack of knowledge about actual team learning behaviours, this study is set up to explore the characteristics of the actual observed basic team learning behaviours and facilitating team learning behaviours more in-depth of three project teams.

Design/methodology/approach: A coding schema is created to observe actual team learning behaviours in interaction between team members in two steps: (1) verbal contributions by individual team members are coded to identify the type of sharing behaviour and (2) when applicable, these individual verbal behaviours are build up to basic and facilitating team learning behaviours. Based on these observations, an analysis of team learning behaviours is conducted to identify the specific characteristics of these behaviours.

Findings: An important conclusion of this study is the lack of clarity about the line of demarcation between individual contributions and learning behaviours and team learning behaviours. Additionally, it is clear that the conceptualisations of team learning behaviour in previous research neglect to a large extend the nuances and depth of team learning behaviours.

Originality/value: Due to the innovative approach to study team learning behaviours, this study is of great value to the research field of teamwork for two reasons: the creation of a coding schema to analyse team learning behaviours and the findings that resulted from this approach. 


\section{Introduction}

Interest in the concept of team learning started booming in research and practice when Senge (1990) stated 'that learning teams are an essential element of a learning organization'. In the years after the publication of Senge's book, an increasing number of studies about this topic were published in different fields of scientific research (for a review see Decuyper, Dochy, \& Van den Bossche, 2010). Team learning was found to have a positive influence on different aspects and levels (individual - team - organisation) of organisational functioning. Within the team itself, its occurrence enhances the emergence of, for example, shared vision about the goal of the team, enhanced knowledge of the skills of other team members, and better team performance on a team level (Boon, Raes, Dochy \& Kyndt, 2013; Edmondson, 1999, 2003; Veestraeten, Kyndt \& Dochy, 2014). It also has positive influences on individual team members. Team learning enhances, for example, individual learning (Sweet \& Michaelson, 1997), self-efficacy and motivation (Johnson \& Johnson, 1994). On an organisational level it enhances, inter alia, continuous growth of the organisation by collective discussions, sharing and building of information, creation of innovative products and actions (Dochy, Gijbels, Raes \& Kyndt, 2014).

Today, more than 20 years of research and practice later, when exploring the field, it becomes clear that the majority of studies on this topic focus on perceptions of team members about the occurrence of team learning behaviours in retrospect. The dominance of research focussing on perceptions of team learning behaviours is the consequence of quantitative survey studies (e.g. Boon et al., 2013; De Dreu, 2007; Edmondson, 1999; Gibson \& Vermeulen, 2003; Hill, Wallace, Ridge, Johnson, Paul \& Suter, 2014; Raes, Kyndt, Decuyper, Van den Bossche \& Dochy, 2015; Savelsbergh, van der Heijden \& Poell, 2009; Van den Bossche, Gijselaers, Segers \& Kirschner, 2006; Van Der Vegt \& Bunderson, 2005; 
Veestraeten, et al., 2014) and qualitative interview studies (e.g. Edmondson, 1999; Gibson \& Vermeulen, 2003) on this topic. When using questionnaires or interviews, the focus of research is by definition on how team members perceived the occurrence of team learning behaviours. However, team learning behaviours are by definition interactions that emerge out of verbal contributions of individual team members. From this perspective, it is more appropriate to measure the real interplay between individual verbal behaviours at the time of occurrence instead of the retrospective perceptions in order to grasp their nature. A small number of studies have used observation methods to study actual team learning behaviours. For example, Edmondson (1999) observed team interactions as a preliminary method to identify team learning behaviours, like giving feedback and sharing information, within her sample. In later phases, she used questionnaires and interviews to study the behaviours more in depth. More recently, Van der Haar, Wijenberg, Van den Bossche and Segers (2013) created a coding schema to identify team learning behaviours based on verbal interaction of team members in a command and control team. However, none of these studies have used the observation method to study identified behaviours with more depth. Additionally, the dominance of research into perceptions of team learning suggests a lack of that aims at understanding the team learning processes (Newman \& Benz, 1998). The set-up of the current study addresses the identified lack: the main goal is to explore the characteristics of basic and facilitating team learning behaviours based on the observation and analysis of real verbal interactions of individual team members. Applying this specific method allows us to identify more deeply the different facets of basic and facilitating team learning behaviours.

\section{Team learning}

Team learning is expressed through interaction processes between team members during which they organise and integrate interdependent acts or input through cognitive, 
verbal and behavioural activities in order to organise team work effectively and create valuable team output (Marks, Mathieu \& Zacharro, 2001). Based on the systematic review of literature from different research traditions, Decuyper et al. (2010) identified eight fundamental team learning behaviours that they divided into basic team learning behaviours and facilitating team learning behaviours.

\section{Basic team learning behaviours}

Basic team learning behaviours (from here on referred to as BTLB) are behaviours that are directly observable in the interaction between team members. They are an inevitable side effect of working in team towards a common goal (Van den Bossche et al., 2006). The first basic team learning behaviour is sharing. This is the utterance of new information, a vision, a meaning, an idea, a proposal etc. by one of the team members to the other team members who are unfamiliar with this information at the point of sharing, and who listen actively while trying to interpret and understand the given explanation (Decuyper et al., 2010; Web \& Palinscar, 1996). Individual contributions in the form of new information, skills, knowledge, and ideas of different team members are a fundamental starting point for learning as a team (Kozlowski \& Ilgen, 2006; Sessa \& London, 2010). When different team members engage in the act of sharing information, and additionally team members build upon, confront and expand the information that is shared in the team, team members start engaging in learning behaviours such as co-construction and constructive conflict. Co-construction is the process of the mutual creation of knowledge by refining, building on or modifying the information, knowledge, and competences shared by one of the team members (Baker, 1994). Constructive conflict is what occurs when team members encounter a conflict or discussion as a consequence of their diversity and the open communication in which this diversity is exposed. However, not the conflicting opinions or knowledge itself, but the act of 
constructively integrating different viewpoints towards a new and better solution is what defines a constructive conflict. The occurrence of one or multiple disagreement(s) of some sort which, in first instance, do(es) not lead to accepting the shared information, but to discussing the conflicting pieces of information, is the main differentiating feature between co-construction and constructive conflict.

\section{Facilitating team learning behaviours}

Facilitating team learning behaviours (from here on referred to as FTLB) are of a different order than BTLB. These processes have the potential to create what popular literature refers to as ' $1+1=3$ ' or team synergy. They make it possible for the team and team members to transcend the effectiveness of the sum of the efforts of individual team members (Decuyper et al., 2010). The first facilitating team learning behaviour, team reflexivity, refers to the team's action of reflecting on the current reality and on how to adapt to the current and future reality in order to achieve the team goals (Senge, 1990; West, 2000). While engaging in team reflexivity, teams build shared cognition about the team goals, about the ways to reach them and about the process of working towards their goals (Decuyper et al., 2010). Team reflexivity can be seen as a process of double loop learning within the team (Agyris, 1977). Teams that engage in team reflexivity are not only able to question the extent to which they achieved or are achieving their goals; they also question their goals, their approach to reach them, the underlying conditions and the established way of working together. It occurs in the form of, for example, planning, evaluation, feedback and reflection. Team activity is a second facilitating team learning process. It occurs when different team members take joint action to work with each other physically and/or psychologically (e.g., Kinny et al., 1994). As a consequence of working together the team members and teams can learn, either directed/planned or undirected/unplanned (Arrow, McRath \& Berdhal, 2000). While 
exploring new perspectives and ways of working, the team can learn from testing and intelligent failures that can result from this (Edmondson, 2013). Intelligent failure, or the unsuccessful trials that occur as part of thoughtful experiments, is inevitable and necessary when experimenting with new approaches because it provides the team with useful new information about what works and what does not work (Edmondson, 2013). Finally, boundary crossing is the team taking initiative to cross its borders; that is sharing and asking for information and feedback with/from other individuals or units outside of the team (Kasl et al., 1997). Teams can, for example, address experts on a certain topic or look for guidance to facilitate their work process as a team.

\section{BTBL versus FTBL}

BTLB can be described as what actually happens when teams learn. The basic team learning processes entail actions such as giving information, asking questions, providing feedback, creating a dialogue, (re)framing of information etc., and lead to the creation of a joint dialogical space as a context for high quality interaction between team members. They generate change through inserting or mutually building new knowledge, however without necessarily leading to improvements (Sessa \& London, 2008). The facilitating team learning behaviours drive the learning of a team in the direction of growth through planning and experimenting; they provide an appropriate context for the basic learning processes to lead to enhanced team performance and functioning. Even though these two types of processes are conceptualised as separate processes, they have to be seen as intertwined processes. The basic team learning processes are an essential part of exerting team reflectivity, team activity and boundary crossing (Decuyper et al., 2010). 
Topic of team learning: task, process and social learning

Starting from this observation that definition of team learning behaviours does not include the type of information that is communicated using the different team learning behaviours, Jehn and Rupert (2008) created a typology of the three possible topics of team learning. Teams that engage in task learning improve their understanding of the task by sharing, confronting and disagreeing on information that is related to the task. Task learning leads to enhance to improved team performances through acquisition of task-related knowledge of the team. When teams are engaged in process learning the focus of the team members' interaction is on learning how to work together as a team and how to structure their efforts in an efficient and well-functioning way (e.g., work routine, role definition, delegation of issues). If process learning is focused on looking at what is necessary for the team to become more efficient it helps the team to reach its goals. Additionally, there is a third possible topic of learning. Social learning can be recognised when the team members learn about personal information of team members like their character, personal life, (work)habits etc. and additionally learn to understand the other's behaviour. Social learning enhances familiarity and understanding of each other's motives for behaviour; it can create empathy and facilitates relational interaction with other team members (Huckman, Staats \& Upton, 2009; Jehn \& Rupert, 2008). This type of learning facilitates collaboration, which in turn leads to higher team effectiveness and efficiency (for an overview of beneficial effects, see Jehn \& Rupert, 2008).

\section{The present study}

The main goal of this study is to examine the characteristics of the actual team learning behaviours by means of studying real team interactions instead of team members' perceptions of team learning behaviours. Starting from the definition of team learning behaviours and the 
items that are used to measure them in previous questionnaire research (Boon et al., 2013; Savelsbergh et al, 2009; Van den Bossche et al, 2006; Veestraeten et al., 2014) a coding system is created to identify the actual team learning behaviours by studying actual team interaction starting from sequences of observed individual verbal contributions. This study addresses following research questions:

1. Which characteristics and mechanisms of basic team leaning behaviours can be recognised based on the observation of verbal interaction of team members?

2. Which characteristics and mechanisms of facilitating team learning behaviours can be recognised based on the observation of verbal interaction of team members?

\section{Method}

\section{Participants.}

To answer the research questions above, three team meetings (the first, middle and last meeting over a period of three months) of three student project teams were audiotaped and coded. Project teams are defined as teams that are working on one-time projects that require unique solutions (Cohen \& Bailey, 1997; Devine, 2002). The student teams were composed in the context of a course on Labour Pedagogy during which they collaborated to solve an authentic organisational problem within a timeframe of three months. The set-up and task of these student teams was very similar to the context of work teams. The student teams were self-directed and self-responsible for their end product, their approach to the task and their collaboration process. They were encouraged to take ownership of their project and were free to take autonomous decisions, while taking into account the context of the questions and wishes of the organisation. They received coaching from the university in the form of feedback on task progress and facilitation of process aspects of collaboration. All the participants signed an informed consent that stated that they voluntarily take part in the study 
and that they are aware that the collected data materials are used for research purposes. They recognised that $100 \%$ confidentiality is guaranteed in terms of reporting of the data. To ensure this confidentiality, the quotes used in the result section of this study are made anonymous.

\section{Method of analysis.}

In order to gain more insight in the team learning processes, directed qualitative content analysis was used. This approach reflects the natural paradigm of small group research that recognises the dynamic complexity of reality in team research (Frey, 1994). Directed content analysis is a classification process of coding and identifying themes or patterns within existing text files with the intention to verify and extend existing theories or conceptual frameworks. The method of analysis and the creation of the coding scheme are guided by an existing theory of team learning. Starting from the basis that is provided by existing theory, the analysis is further developed while working on and with the data (Hsieh \& Shannon, 2005).

In total eighteen hours of audio material were analysed using the Observer $®$ XT 10 software. The Observer® XT 10 software facilitates the analysis of the audio data by allowing direct coding while listening to the audio files. The software provides the coded output in an excel file that can be used for further analysis. Team learning behaviours are per definition behaviours that occur in a team, to which team members contribute with individual verbal behaviours. As a consequence, two steps had to be taken to be able to identify team learning behaviours based on the coded individual verbal contributions.

Coding of the individual verbal behaviours. First, the individual behaviours of team members were coded. Two coders - the first two authors of this article - created a coding system (see appendix 1) consisting of labels for individual verbal contributions. The unit of coding is set 
at representing an idea, argument chain, discussion topic, or a representation of a single topic (Strijbos, 2005). The coding scheme was created based on the coding scheme for team learning behaviours of Van der Haar, Wijnenberg, Van den Bossche and Segers (2013). Adjustments were made to the context of project teams using the researchers' knowledge about the context before the coding process started. The scheme was further adapted during a testing phase of coding. To make these adjustments to the coding scheme, both coders separately analysed the same hour of one of the meetings per project team, and compared and aligned their analyses through extensive and thorough discussion and elaboration about the different assigned codes. Using this procedure, it was assured that the scheme was adapted to the context and that both coders had the same understanding of the different codes. After agreement on the coding scheme, the remaining audio material of the team meetings was divided between the two coders and each of the meetings was coded by one of the coders. They provided a code for the type of individual contribution and the topic of the unit of speech was determined based on the classification of Jehn and Rupert (2008) for every unit of speech. During this process of coding, both coders were present and they continued consulting each other when in doubt or when they encountered unfamiliar units of coding in the data.

Coding of team learning behaviours. In the following step, BTLB and FTLB were identified. For each type of behaviour a different identification method was used.

$B T L B$. In order to constitute the BTLB based on the individual verbal behaviours, the definitions described in the theoretical overview of this study were used and supplemented with information from the items retrieved from previous questionnaire studies on team learning (see appendix 2). Sharing is identified as 'information simple fact', 'information 
interpretation', 'information anticipation', 'proposal' 'question clarification', 'question challenge' and 'disagreement'. Only sequences of individual units of speech that build upon each other within the same topic are considered co-constructive learning behaviours. Previous research suggests that co-construction that ends with a mutual agreement between team members leads to the creation of mutually shared cognition in the team (Van den Bossche et al., 2006). Therefore a distinction was made between co-construction with or without wrapup. When one of the team members expressed a disagreement and this was followed by a sequence of sharing behaviours, this sequence was labelled constructive conflict. Similar as to the structure of co-construction behaviours, mere disagreement as a part of a sequence of units of speech was not sufficient to identify constructive conflict.

$F T L B$. As a starting point the same approach is used as for the identification of BTLB: construction of the FTLB based on the individual verbal behaviours, the definitions described in the theoretical overview of this study and information from the items that were used in previous questionnaire studies on team learning (Edmondson, 1999; Hirst \& Mann, 2004; Savelsbergh et al., 2009). For an overview of the items see appendix 2. In literature, an explicit distinction is made between team reflexivity about the task and about the process. This specification is not made for boundary crossing and team activity. However, given the conceptualisation of these concepts, it can be assumed they can be applicable to all topics of learning. Team reflexivity about the task is identified when different team members consider different aspects of the task and task process by reviewing objectives, used methods or current work on their suitability for achieving current team goals, and by discussing future goals. Additionally, team reflexivity about the process can be identified when the team members consider their work routines and communication within the team. Team activity can be seen as taking action as a team and learning from this. In this study, verbal behaviours that express 
the intent of experimenting and taking an action in terms of mobilising team members to work together (planned or unplanned) were coded as team activity. Intentional exchange of and search for information/opinions/ideas with/from others external to the team or to other teams was coded as boundary crossing (Edmondson, 1999).

\section{Results}

In this section an overview of the findings concerning characteristics of team learning behaviours based on studying the individual verbal behaviours is given. First, the results concerning the structure and composition of BTLB is presented; next a similar overview is presented for FTLB.

Characteristics and mechanisms of basic team leaning behaviours that were found based on the observation of verbal interaction of team members.

Three categories of sharing behaviours. In Table 1 the different forms of observed sharing behaviours are outlined accompanied by an example from one of the analysed team meetings ${ }^{1}$. All these individual verbal behaviours can be identified as sharing behaviours, because they give information about the task or about the perception of an individual team member on this information. Depending on the intention of the sharing team member, three categories of sharing behaviours can be distinguished (see Table 1). The first type is intentional sharing of new information to the rest team. This intentional information in-flow exists in different forms: from plain information sharing to sharing information into the team coloured with a personal opinion or interpretation. The second type is a verbal contribution

\footnotetext{
${ }^{1}$ For the examples only task statements were used, unless mentioned differently (cfr. infra for an elaboration on the content of team learning behaviours).
} 
that is not necessarily expressed with the intention to give information, however, it has this effect. A by-product of verbal behaviours like making a decision, disagreeing or proposing something is that they provide information to the other team members, mostly about the speaker's opinion on certain matters. Another type of sharing behaviour is a verbal behaviour that functions as a trigger for more information inflow from other team members. For example 'question for clarification' or 'a question to challenge other team members', has the potential to create more information inflow.

\section{[insert Table 1]}

Characteristics of co-construction and constructive conflict. The other two BTLB (coconstruction and constructive conflict) consist out of a sequence of individual sharing behaviours. The differentiating feature between a mere sequence of sharing and the two BTLB, the act of team members building further on others team members shared information is crucial. Additionally, the analysis showed that co-construction and constructive conflict have most of their characteristics in common, except for the one that distinguishes constructive conflict from co-construction. The differentiating feature between coconstruction and constructive conflict is that the latter starts with an expressed disagreement by one of the team members. During the analysis, different reactions to disagreement were found (see Table 2). However, constructive conflict only emerges when the different opinions trigger team members to start a constructive discussion.

[insert Table 2]

In the following paragraph, the discovered characteristics of co-construction and constructive conflict are described. The described characteristics account for both types of 
BTLB. Therefore, from now on they are both referred to with the term (conflictual)

construction.

First, the number of team members taking part in the (conflictual) construction varies from two to all the team members. Second, a distinction can be made based on topic (task/process/social). A single team learning behaviour can deal with one type of topic (task, process or social) or there can be a switch between two types of topic (see box $1 \& 2$ for examples).

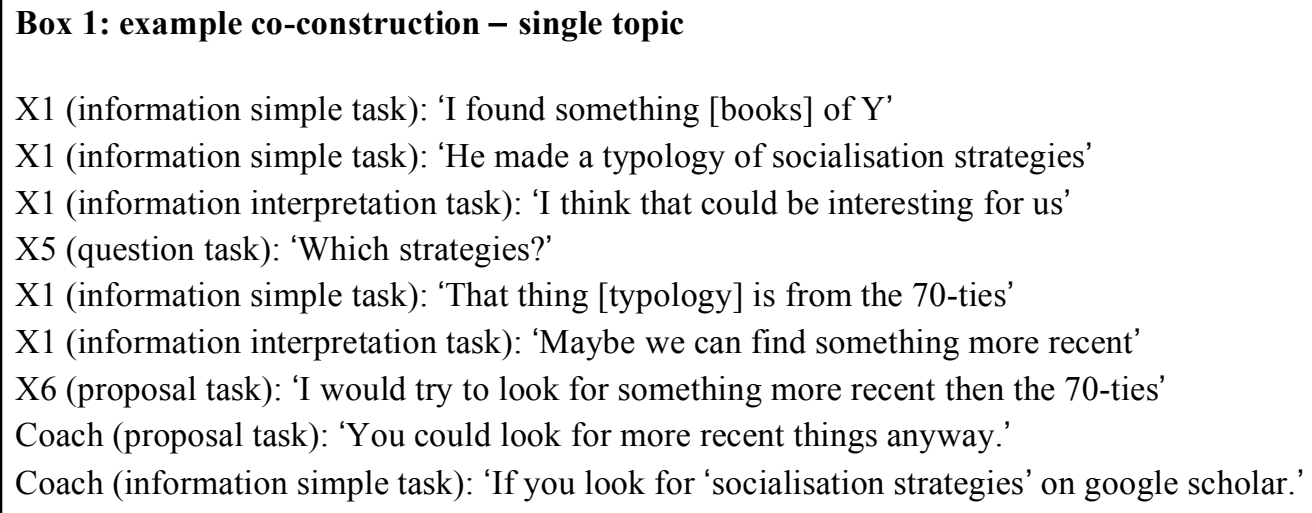

\section{Box 2: example co-construction - mixed topic}

$\mathrm{X} 2$ (proposal process): 'Or maybe one person can do it, I don't know'

$\mathrm{X} 4$ (information anticipation process): 'If you also want to write the results, you have to do it with two persons'

X2 (decision process): 'Two people do the research method'

Coach (disagreement process): 'But I think it is interesting to wait for the results'

Coach (proposal tasks): 'Then you can say: we saw this and it is confirmed or not'

X4 (affirmation task): 'Ok'

Coach (proposal task): 'Then you can integrate your results and discussion'

X6 (information simple task): 'So this [research method] only handles about why we use this method?'

X2 (affirmation task): 'Correct'

Additionally, some of the (conflictual) constructions end with a wrap-up and others do not. Two types of wrap-up are observed: first, a wrap-up can entail that team members form an agreement about something, for example, the understanding of a theory or assignment. This occurs when the (conflictual) construction is cognitive in nature. It deals with information and knowledge team members know or need to know. On the other hand, a 
(conflictual) construction can end with a decision that implies an action; e.g. the wrap-up is an agreement about the deadline or about the way to handle something (see box 3 ). When (conflictual) construction ends without a wrap-up, it means that no agreement or decision is made concerning the topic of the (conflictual) construction. Wrap-up can be implicit, when one team member expresses the wrap-up and the rest does not explicitly react to counter it. Wrap-ups can also be explicit. This occurs when one team member expresses the wrap-up and one or more other team members confirm with an affirmation. When a (conflictual) construction is characterised by a wrap-up, it can be at the end of the behavioural sequence (see box 3).

Box 3: co-construction with wrap-up, explicit, not embedded

X6 (proposal task): 'We should move a piece of text from the result section to the organisation-analysis section'

$\mathrm{X} 4$ (question task): 'Are you talking about the organisation structure?'

$\mathrm{X} 6$ (information simple task): 'Yes this is about the organisation culture'

$\mathrm{X} 4$ (affirmation task): 'Indeed, that would fit better in the organisation analysis'

X7 (information simple task) '[But] in the section about the actors, three points are discussed, but now only one is left'

X7 (proposal task): 'So we thought it would be better to leave the part about the actors out all together' X2 (information interpretation): 'I think it [the piece of text talked about] also suits better with the organisation analysis'

X5 (information interpretation task): 'And that should be written based on the literature'

X5 (question process): 'Isn't this all starting to get a little bit much [work]?'

$\mathrm{X} 6$ (information simple task): 'The thing is: all the information is there already'

X6 (information interpretation task): 'So, I think it is better if it is in the organisation analysis'

X6 (proposal task): 'And that we delete our part of about the actors'

X6 (information simple task) 'Otherwise we only have this'

X2 (affirmation taks): 'I would do it that way'

The wrap-up can also be embedded within the behavioural sequence, which means that different implicit and/or explicit wrap-ups are made during the co-construction different subtopics are discussed and some of the subtopics end with an explicit wrap-up while others do not (see box 4). 


\section{Box 4: example co-construction with subtopics and different types of wrap-up}

(Context: team members state that there is no explicit information about the organisation analysis and explain which information can be found on the topic. The other team members implicitly agree on this by not objecting. Later, other team members explicitly agree about the wrap-up of the last subtopic, namely 'what is meant by professionalization?')

X1 (information simple process): 'For the organisational analysis: I did some research about those grants' $\mathrm{X} 1$ (information interpretation task): 'But there I can't find anything about that. The only thing I can find is that the organisation hands out grants itself.'

Coach (question task): 'Grants or what [are you talking about]?'

$\mathrm{X} 2$ (question task): 'Was that for your organisational analysis?'

$\mathrm{X} 2$ (information interpretation task): 'I could find almost nothing [no information] for the organisational analysis.'

Coach (question task): 'Did you already get guidelines for the organisational analysis?'

$\mathrm{X} 1$ (affirmation task): 'Yes'

$\mathrm{X} 1$ (information simple task): 'It is stated in the PowerPoint'

Coach (question task): 'Is there something about that in the study guide?'

$\mathrm{X} 1$ (affirmation task): 'No'

X6 (affirmation task): 'No'

X6 (information interpretation task): 'It is weird that nothing can be found about the organisational analysis in the study guide.'

X5 (information interpretation task): 'It is about learning goals, but nothing very specific'

X4 (information simple task): '[There is] nothing about the organisational analysis.'

$\mathrm{X} 4$ (question challenge task): 'I don't understand what they mean with professionalisation of labour pedagogy'

$\mathrm{X} 1$ (information interpretation task): 'Maybe it is about if labour pedagogists work there, I don't know?'

X6 (affirmation task): 'No.'

$\mathrm{X} 6$ (disagreement task): 'What there education is.'

$\mathrm{X} 7$ (information simple task): 'What their diploma is.'

$\mathrm{X} 4$ (information simple task): 'Yes, what their education is.'

X4 (affirmation task): 'Yes.'

X6 (information simple task): 'Relatively high level of education.'

(Conflictual) construction without wrap-up exists in different forms. First of all, in some cases the (conflictual) construction is interrupted (see box 5).

\footnotetext{
Box 5: co-construction without wrap-up - interrupted

X2 (proposal process): 'Maybe everybody should look for texts that he finds really interesting.'

$\mathrm{X} 2$ (proposal process): 'And post them on Toledo, making sure everybody can read them'

X6 (affirmation process)

X6 (proposal process): 'We have to make sure that we don't select the same texts'

X6 (information anticipation process): 'But what if you type that into Google, everybody will come with the

5 first texts'

$X 7$ (question challenge task): 'What should we do for the project text?
} 
(Conflictual) construction without wrap-up can also occur because the team members lack the knowledge to discuss the issue at hand. In most of these cases, a plan of action is formulated (e.g., one of team members suggests to ask an outsider for information or help) (see box $6 \& 7$ ).

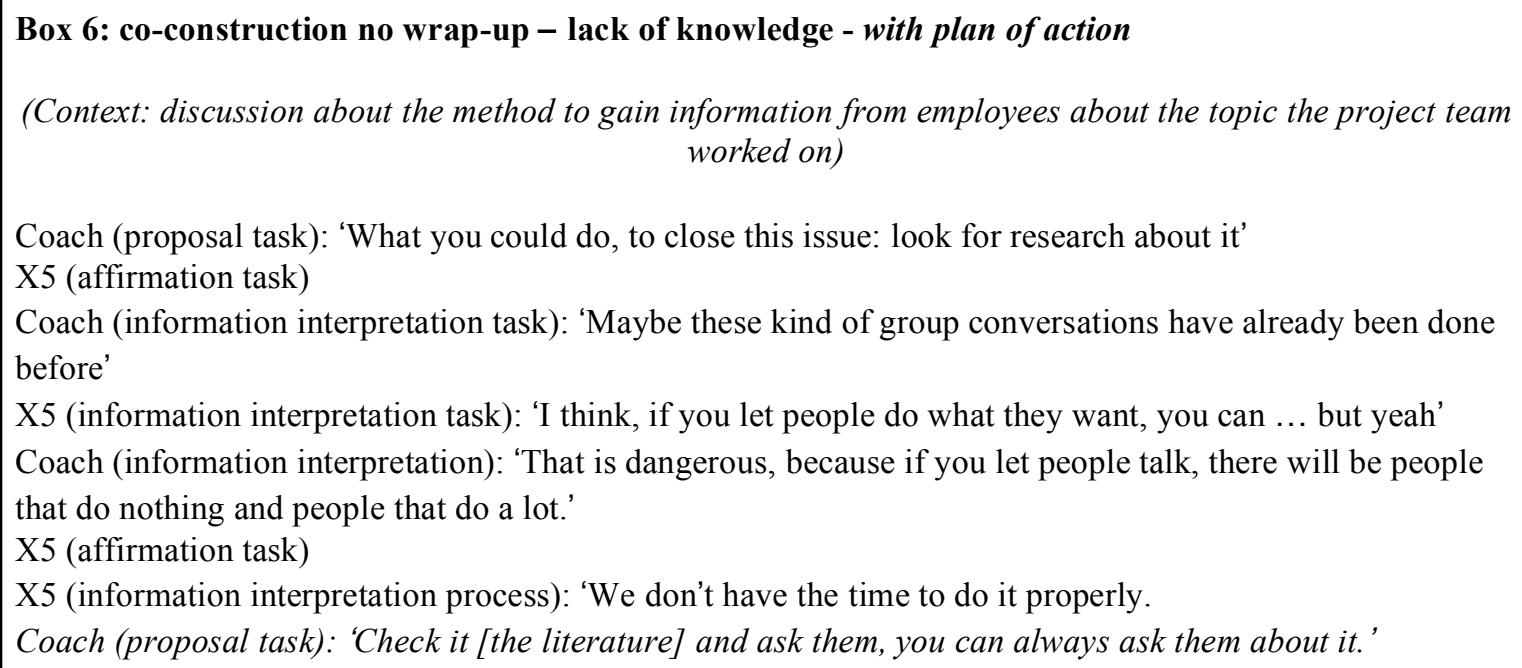

Box 7: co-construction no wrap-up - lack of knowledge - without plan of action

X3 (information interpretation task): 'Do you think that these people will fill out the questionnaires?' X6 (information simple task): 'They are obliged to complete the checklist and even that they don't complete X6 (information anticipation task): 'Then I ask myself: what will they do with a questionnaire?'

X5 (affirmation task): 'Yes, online questionnaires will not be completed.'

$\mathrm{X} 7$ (proposal task): 'We can pass by if necessary'

X5 (question task): 'At the school? You mean we have to stand next to them when they fill it out?'

$\mathrm{X} 7$ (proposal task): 'I mean, you could say: by the end of the day we pick them up'

Coach (proposal task): 'You can mail them to Lieve'

X7 (affirmation task)

Coach (information interpretation task): 'If one gets a paper on their desk, one will complete [the questionnaire] easier.'

X7 (affirmation task)

Coach (question social): 'I don't know what you guys do with those e-mails from master students'

Coach (information simple social): 'But me, I would throw them right into the bin'

X5 (information simple social): 'I complete them'

The conversation continues about what individual team members do with this type of e-mails, but no decision is made.

(Conflictual) construction without wrap-up also occurs because team members do not feel the need to make a decision or take action (yet) (lack of need) (see box 8). 


\section{Box 8: co-construction without wrap-up - lack of need}

(Context: In this example, the team members are brainstorming about possible products. At the point of discussion an actual decision is not necessary yet.)

X5 (proposal task): 'If we make a checklist that is personalised per department.'

X5 (information interpretation task): ' . . because for the guys from the logistics department, some of these issues will be redundant because those guys have good connections among themselves.'

X4 (affirmation task): 'Yes'

$\mathrm{X} 1$ (disagreement task): 'I think it is difficult to compare the guys from the logistics department with others, they are friends, so mentorship is like friendship.'

X5 (information interpretation task): 'I think that is a characteristic of this logistics department [and you will not encounter it anywhere else].'

$\mathrm{X} 1$ (affirmation task): 'yes'

$\mathrm{X} 1$ (information interpretation task) 'That is why I said it'

X5 (information interpretation task): 'I think every department is like that to some extend [they all of their unique characteristics].'

X4 (affirmation task)

The conversation switches to the next product proposal

Lastly, in some cases it seems that a wrap-up is not present: for example, when team members

are simply sharing information with each other, but they are also building further on the information somebody else shared before (see box 9).

Box 9: co-construction without wrap-up - irrelevant

(Context: sharing information about how team members filled out the personal profiles)

X6 (information simple task): 'I added information like negative characteristics, positive characteristics. I don't know if we are supposed to do that.'

Coach (information simple task): 'If they don't need it, they won't use it'

X5 (information simple task): 'I added the school I've been to and things like that'

X6 (affirmation task): 'oh yeah'

X6 (information simple task): 'I could add that'

Coach (information simple task): 'If they don't need it [the information], they won't use it'

X6 (information interpretation task): 'yes, especially the extended information'

$\mathrm{X} 7$ (information interpretation task): 'Mine is not that extended, but anyway'

Characteristics and mechanisms of facilitating team leaning behaviours that were found based on the observation of verbal interaction of team members.

As stated earlier, the interrelation between BTLB and FTLB is rather complex.

However, based on the analysis of the data it was found that team members use BTLB to 
exert certain FTLB. To identify FTLB based on verbal behaviour of team members, it is necessary to take into account the content of the verbal behaviour.

The build-up of team reflexivity. Team reflexivity is directly identifiable through observing the content of sharing, co-construction and/or constructive conflict behaviours between team members. If the content of a BTLB is characterised by a reflection about the team task, the team processes or interaction between team members, the BTLB can be labelled team reflexivity. The typical build-up for team reflexivity consists of a trigger for team reflexivity that is created by one of the team members expressing the need for reflection or asking a question that triggers reflection in the form of a sharing behaviour. Next, one or more other team members address the issue. In that case, a (conflictual) construction emerges (with the same characteristics as described above). However, when none of the other team members react to the trigger or when other team members appoint it as irrelevant, no team reflection emerges. Team reflexivity about the team process entails, for example, questioning work routines or plans that were earlier agreed on (see box 10). Team reflexivity about the task entails, for example, questions about whether or not certain content is interpreted correctly or a certain topic is handled correctly. Additionally, when team reflexivity ends with a wrap-up it is often an expressed intention for team activity (see box 10). 


\section{Box 10: team reflexivity with intention for team activity as outcome}

X6 (question challenge process): 'And what about the structure of the meeting, what did you think of that?'

$\mathrm{X} 1$ (information interpretation process): 'It could have been better'

X6 (information interpretation process): 'We wandered a bit.'

$\mathrm{X} 1$ (affirmation process)

X5 (information interpretation process): 'That is inevitable'

X4 (information anticipation process): 'I think it would be better that when we close an agenda point, that we actually close it'

X6 (information interpretation process): 'I think that we will otherwise ... [sentence is not finished]'

$\mathrm{X} 2$ (proposal process): 'maybe we should write down the agenda points next time'

$\mathrm{X} 5$ (affirmation process)

X6 (proposal process): 'We can agree that we follow the agenda points and that we go around the table at the end of the meeting, to make sure everybody has the opportunity to say what has to be said'

X6 (information interpretation process): 'Because sometimes there are small things that are said in between and then you have the opportunity to ask about it at the end'

X6 (information anticipation process): 'If everybody agrees! Then you can remember these things and address them at the end of the meeting'

Emergence of team activity. Following the definition of team activity and based on the analysis of the observations, it can be stated that (conflictual) construction can be classified as (a form of) team activity. During these (conflictual) constructions the team members are combining their means to progress as a team on different levels: task - process - interpersonal (as example, see boxes 1-10). Additionally, team activity can also be observed when team members actually take action. As in the case of team reflexivity, one of the team members creates a trigger. When other team members react and build further on this trigger, a (conflictual) construction that entails team activity emerges (see box 11). 


\section{Box 11: team activity - process- trigger in italic}

(Context: after a reflection about the efficiency of the meeting, one of the team members asks if there is anything else they can do to improve the efficiency.)

X6 (question challenge process): 'Are there any suggestions we can take with us?'

$\mathrm{X} 4$ (proposal process): 'To do list at the end of the minutes'

$\mathrm{X} 2$ (information simple process): I already did that'

X4 (affirmation process)

X3 (information interpretation process: 'Then we don't need to read the minutes completely to know what we have to do.

$\mathrm{X} 1$ (question process): 'You mean in the miscellanea or in the agenda?'

$\mathrm{X} 4$ (disagreement process): 'No I mean that the end of the minutes, so we can easily see what we agreed on.'

$\mathrm{X} 3$ (affirmation process): 'I also think that is better'

Boundary crossing as a shard decision for action. The findings concerning the observation of boundary crossing in verbal behaviour are limited to, with one exception, observation of the decision to ask a question or ask for information to somebody outside of the team. Typically, the decision for boundary crossing is expressed by one team member and can (implicitly) be confirmed or not by other team members. Boundary crossing is often suggested as a plan of action for a (conflictual) construction when the team feels it lacks knowledge to wrap-up the (conflictual) construction (see box 7). However it can also be expressed as a shared decision during a (conflictual) construction. As is the case with team reflexivity and team activity, one team member can express the need for boundary crossing and the other team members can or cannot respond to this suggestion or decision. Another way to recognise boundary crossing, next to the expressed decision to do so, can be found when team members insert information they received from sources outside of the team into the team. This can be seen as confirmation of exertion of boundary crossing behaviour in retrospect. As an example, the team collected information from different employers and employees by means of interviews and used this information to work with. In the case that an external party is present during the team meeting, boundary-crossing behaviour with this external party is shaped by (conflictual) construction. For example, when a coach of the project teams gives feedback on one of their 
products, this can end up in an interaction between (some of the) team members and the coach that entails discussion and clarification.

\section{Conclusions \& discussion}

The different insights about the BTLB and FTLB generated as a consequence of the analysis of this study are described in the following paragraphs. Additionally, a discussion is set up to critically reflect on these conclusions.

First, all forms of individual verbal behaviour can be considered sharing. In previous research, sharing is considered as a team learning behaviour next to co-construction and constructive conflict (Decuyper et al., 2010). However, other researchers consider sharing as an individual behaviour, not as team behaviour (e.g., Kostopoulos, Spanos, \& Prastacos, 2013). They state that more attention should be given to the distinction between individual behaviour and team behaviour in research on team processes. Team learning can be seen as an emergent process that starts from individual action (Kozlowski \& Klein, 2000). In this study it could clearly be observed that sharing behaviours are contributions of individual team members that have the potential - when they are the onset of a sequence of successive and constructive verbal behaviours that construct meaning - to form a (conflictual) construction. The different types of sharing of behaviours through which team members can express their knowledge, motives and attitudes shape these individual actions. When individual team members share information and the other team members actively process the expressed information and act upon it, team members engage in the action of construction of meaning and it can that be considered team learning (as defined by Van den Bossche et al., 2006). Additionally, it was found that team members could also engage in verbal behaviours that facilitate sharing behaviour from other team members, e.g. asking questions, which also has the potential to trigger team learning behaviours. Taking this distinction into account could 
have positive repercussions for measuring, observing and analysing these behaviours and processes more precisely.

Furthermore, it was found that the number of team members that actively participate in (conflictual) construction and FTLB sequences varies from two to the total number of team members in the team. Additionally, they always originate from an individual contribution of one of the team members and is in some cases limited to the contribution of one team member (e.g. a decision to engage in boundary crossing behaviour). This raises the question how many team members should actively be involved in a (conflictual) construction in order to talk about team learning behaviour. Additionally, what about the other team members who do not actively contribute but are a part of the conversation in a passive matter (listening and following the conversation)? Are they in such a way part of the team learning sequence that it can have consequences for the output like shared cognition or team effectiveness? And how can this be observed? The two issues discussed above call for a clear definition of team learning behaviours that separates individual behaviours that potentially contribute to team learning, from the actual team learning. This offers perspectives for more fine-grained research and more effective facilitation methods for (individual behaviour in) teamwork.

Additionally, different findings were generated concerning the characteristics of (conflictual) construction. One sequence of (conflictual) construction can entail several topics. In their team learning typology Jehn and Rupert (2008) differentiate between three types of topics of team learning (task/process/social) depending on the subject of team learning. However, the findings in this study show that in some cases there is a high interrelation between different types of learning within one (conflictual) construction. When setting up research for types of team learning behaviours, this should be taken into account.

A third finding is that verbal construction of co-construction and constructive conflict based on individual verbal statements is very similar in nature. The two differentiating aspects 
between both types of BTLB are (a) the exertion of a disagreement by one of the team members, and (b) a constructive reaction of (one or more) other team member(s) to this disagreement. A disagreement can be seen as a trigger created by one of the team members, an entry for the team to exert the team learning behaviour. An individual team member can express this intentionally or not intentionally. It then depends on the reaction of one or more of the other team members whether constructive conflict emerges. When team members do not approach conflicting individual verbal contributions in a constructive way, team members merely contribute individual conflicting verbal behaviours. This has the potential to escalate in destructive conflict (de Wit, Greer, \& Jehn, 2012). Interestingly, the same mechanism exists for the three FTLB. In this study, they are always triggered by an individual verbal behaviour by one of the team members that has the potential to become a FTLB. For team reflexivity the trigger could entail questioning e.g. the current working routine or method used. The trigger for boundary crossing is the suggestion or action to look for information with people outside of the team. For team activity (experimenting), the trigger can be a suggestion for a new work routine. It seems that, by expressing a trigger, one of the team member creates an opportunity for the team to bring the team functioning to a higher level in terms of really working together as a team and using more of the potential resources that teamwork has to offer. However, it depends on the other team members whether the potential of the trigger is fully used.

Fourthly, it was found that different types of wrap-up exist. These wrap-ups occur in the form of added knowledge or skills to the teams' mental model. However, the can also occur in the form of a decision to take a certain action. These actions can take to form of FTLB, like team activity or boundary crossing. It was observed that not all (conflictual) constructions end with a wrap-up. And, contrary to theory stating that mutual agreement is necessary to build up mutually shared cognition (Van den Bossche et al., 2006) and previous 
research stating that a wrap-up is necessary for the (conflictual) construction to be effective (e.g. Van der Haar et al., 2013), it seems that not every (conflictual) construction needs a wrap-up to be useful. As the example in the result section (see box 8, 9, 10 and 11) shows, in some cases mere exchange of information and building further on each other's knowledge seems to suffice at that moment of the course of the team. It could even be hypothesised that these (conflictual) constructions are fruitful. In the case of box 8 and 9 because a lack of knowledge comes to the surface and, in some cases, a solution to fill the knowledge gap is suggested. In the case of box 10, there is no need for a wrap-up (yet) because it entails an issue that is addressed before a decision should be made or an action should be taken. In the case of box 11 because of mere information exchange, which enhances shared cognition. The type of team studied could also have an influence on this process. Van der Haar et al. (2013) studied command and control teams. These teams do not have the time to elaborate on different topics or search for different alternatives. For them, the most efficient and effective strategy is to make a quick and explicit decision. In the project teams that are studied here, team members have and need the time to discuss and elaborate on different topics. This could explain the occurrence of (conflictual) constructions without wrap-up. However, to know if and how these different types of sequences of (conflictual) construction also build up to team effectiveness, and if there is a difference in effect for the different types of wrap-up on team effectiveness or other outcome measures is subject for further research.

When team reflexivity, team activity or boundary crossing can be identified as the content of a BTLB, they can be referred to as FTLB. Based on the observation of verbal behaviours of team members, it was possible to identify team reflexivity when it occurred. For team activity and boundary crossing, it was possible to identify the behaviours when they occurred during the meeting and the intention team members expressed to exert these behaviours in the future. Additionally, boundary crossing and team activity were often 
suggested as a plan of action from (conflictual) construction without a wrap-up. Lastly, as for team reflexivity, both boundary crossing and team activity could consist out of task and/or process contents.

The observation of team learning behaviours is a method with the potential to create more fine-grained and nuanced knowledge about team learning processes. Applying this method ensures a higher ecological validity of study than earlier questionnaire research because the actual behaviours are measured instead of team members' perception of the occurrence of the behaviours. Given the discrepancies between the initial coding scheme of Van der Haar et al. (2013) and the coding scheme developed in this study and following the naturalistic paradigm (Frey, 1994), attention should be given to team type and team task when setting up a method to code both individual verbal inputs and team learning behaviours. The coding scheme that was created is an appropriate tool to identify BTLB. Based on the findings about the characteristics of BTLB in this study there are different possibilities to amplify or simplify the coding scheme depending in the interest of the researcher. For example, it is possible to limit the coding to different types of wrap-ups of (conflictual) constructions and focus on the effect on team performance.

\section{Limitations}

Both this study itself as the topic of this study (the method of observation of team learning behaviour) has limitations. The main limitation of this study is that the findings are based on three project teams, which makes the generalizability questionable. However, the findings were very consistent over the three project teams. And the small sample also creates the opportunity to get very fine-grained information about team learning behaviours. Related to this, the main limitation of this coding method of analysis is that it is time-consuming to apply due to its detailed approach. 
The most important limitation concerning this method of observation is that it is limited to the observation of individual verbal behaviours. The coders only relied on what was explicitly verbally stated by team members. Despite the importance of non-verbal behaviour, like body language, and unexpressed opinions to understanding individual verbal behaviours, they were not included in this study. This could have implications for the accurate observation of implicit wrap-up or (conflictual) construction without wrap-up. In the first case, when none of the team members counters a wrap-up formulated by one of the team members, it could mean that they agree. However, it could also mean that they are afraid to disagree due to, for example, the absence of a safe climate in the team.

Lastly, in this study not attention is given to which types of team learning behaviours and how many of these behaviours actually occurred in the observed project teams. And to what extend this informs us about performance of the teams. This information lies beyond the scope of this article and will be addressed in further research.

\section{Implications for theory and practice}

When comparing the results of the current study to the existing theory about team learning and previous questionnaire research investigating team learning processes, it can be stated that more detailed knowledge was created concerning the characteristics of the different types of BTLB and FTLB that were observed. This enhances the insights in theory of team learning behaviour, specifically concerning the distinction between individual contributions to the team and team learning efforts. This creates a range of new opportunities to enhance the quality of data collection and related insights on team learning behaviours, both quantitative and qualitative.

Additionally, this information provides a basis to enhance our knowledge about the facilitation of team learning behaviour in practice. Teamwork is a fundamental building block 
in the organisation of work in contemporary workplaces. Strangely enough the main focus of organisational training and coaching systems is still on the individual employee and employees are still rewarded based on his/her individual contribution. These practices are not supportive for knowledge sharing between employees and as such an obstacle for the occurrence of team learning behaviours (Bartol \& Srivastava, 2002). The focus on teamwork is slowly but surely causing a shift in the strategy of rewarding systems within organisations (Cacioppe, 1999; Kerrin \& Oliver, 2002). The implementation of team rewards triggers an enhanced focus on team coaching towards better performance. This study provides valuable information to set up coaching actions to facilitate effective team communication patterns. Team learning behaviours such as reflexivity are known to have a positive effect on the functioning of the team. If team members are made aware of the existence of a trigger for the creation of such team learning behaviours, they can be trained to recognise triggers or create triggers themselves. This could have the potential to facilitate the occurrence of team learning behaviour and enhance team effectiveness. 


\section{References}

Agyris, C. (1977), “Double loop learning in organizations", Harvard Business Review, Vol. 55 No. 5, pp. 115-125.

Arrow, H., McGrath, J.E. and Berdahl, J.L. (2000), Small groups as complex systems: Formation, coordination, development and adaptation, CA, Sage.

Baker, M. (1994), "A model for negotiation in teaching-learning dialogues”, Journal of Artificial Intelligence in Education, Vol. 5 No. 2, pp. 199-254.

Bartol, K.M., \& Srivastava, A., (2002), "Encourage knowledge sharing: The role of organizational rewards systems. Journal of Leadership and Organization Studies, Vol. 9, No. 1, pp. 64-76. doi:10.1177/107179190200900105

Boon, A., Raes, E., Kyndt, E., \& Dochy, F. (2013), "Team learning beliefs and behaviours in response teams", European Journal of Training and Development, Vol. 37 No. 4, pp. 357379. doi:10.1108/03090591311319771

Cacioppe, R. (1999), "Using team-individual reward and recognition strategies to drive organisational success", Leadership \& Organization Development Journal, Vol. 20 No. 6, pp.322-331. doi:10.1108/01437739910292634

Cohen, S.G. and Bailey, D.E. (1997), "What makes teams work: Group effectiveness research from the shop floor to the executive suite", Journal of Management, Vol. 23 No. 3, pp. 239290. doi: $10.1177 / 014920639702300303$

Decuyper, S., Dochy, F. and Van den Bossche, P. (2010), "Grasping the dynamic complexity of team learning: An integrative model for effective team learning in organisations", Educational Research Review, Vol. 5 No. 2, pp. 111-133. doi:10.1016/j.edurev.2010.02.002

De Dreu, C.K.W. (2007), "Cooperative outcome interdependence, task reflexivity, and team effectiveness: A motivated information processing perspective", Journal of Applied Psychology, Vol. 92 No. 3, pp. 628-638. doi: 10.1037/0021-9010.92.3.628

De Dreu, C.K.W. and Weingart, L.R. (2003), "Task versus relationship conflicts, team performance and team member satisfaction: A meta-analysis", Journal of Applied Psychology, Vol. 88 No. 4, pp. 741-749. doi: 10.1037/0021-9010.88.4.741 
Devine, D.J. (2002), "A review and integration of classification systems relevant to teams in organizations", Group Dynamics: Theory, Research, and Practice, Vol. 6 No. 3, pp. 291-310. doi: 10.1037//1089-2699.6.4.291

De Wit, F.R.C., Greer, L.L. and Jehn, K.A. (2012), "The paradox of intragroup conflict: a meta-analysis", Journal of Applied Psychology, Vol. 97 No. 2, pp. 360-390. doi: $10.1037 / \mathrm{a} 0024844$

Dochy, F. Gijbels, D., Raes, E., \& Kyndt, E., (2014), "Team learning in education and professional organisations", in Billett, S., Harteis, C., and Gruber (Eds.), International Handbook of Research in Professional and Practice-based Learning, Springer, Dordrecht, The Netherlands, pp. 987-1020.

Edmondson, A.C. (1999), "A model of work-team learning. Psychological safety and learning behaviour in work teams", Administrative Science Quarterly, Vol. 44 No. 2, pp. 350-383.

Edmondson, A. (2013), Teaming, John Wiley \& Sons, Inc, San Fransisco.

Frey, L. R. (1994). The naturalistic paradigm. Studying small groups in a postmodern era. Small Group Research, 25, 551-577.

Gibson, C. and Vermeulen, F. (2003), "A healthy divide: Subgroups as a stimulus for team learning behaviour", Administrative Science Quarterly, Vol. 48 No. 2, pp. 202-239. doi: $10.2307 / 3556657$

Hill, A.D., Wallace, J.C., Ridge, J.W., Johnson, P.D., Paul, J.B. and Suter, T.A. (2014), "Innovation and effectiveness of co-founded ventures: a process model", Journal of Business Psychology, Vol. 29 No. 1, pp. 145-159. doi: 10.1007/s10869-013-9306-9

Hsieh, H.-F. and Shannon, S.E. (2005), "Three approaches to qualitative content analysis", Qualitative Health Research, Vol. 15 No. 9 , pp. 1277-1288. doi:10.1177/1049732305276687 Huckman, R.S., Staats, B.R. and Upton, D.M. (2009), "Team familiarity, role experience, and performance: Evidence from Indian software services," Management Science, Vol. 55 No. 1, pp. 85-100. doi: $10.1287 /$ mnsc. 1080.0921

Jehn, K.A. and Rupert, J. (2008), "Group fautlines and team learning: How to benefit from different perspectives", in Sessa, V.I. and London, M. (Eds.), Work group learning: Understanding, improving \& assessing how groups learn in organizations, Lawrence Erlbaum Associates, Mahaw, New Jersey, pp. 19-148. 
Johnson, D.W. and Johnson, R.T. (1994), Together and alone: Cooperative, competitive, and individualistic learning (4th ed.), Allyn \& Bacon, Boston, MA.

Kasl, E., Marsick, V.J. and Dechant, K. (1997), “Teams as learners: A research-based model of team learning", The Journal of Applied Behavioral Science, Vol. 33 No. 2, pp. 227-246.

Kerrin, M., Oliver, N., (2002), "Collective and individual improvement activities: the role of rewards systems, Personelle Review, Vol. 31, No. 3, pp. 320-337.

doi:10.1108/00483480210422732

Kinny, D., Ljunberg, M., Rao, A., Sonenberg, E., Tidhar, G. and Werner, E. (1994), "Plannend team activity", in Castelfranchi, C. and Werner, E. (Eds.). Artificial social systems, Springer, Germany, Berlin, pp. 227-256.

Kostopoulos, K.C., Spanos, Y.E. and Prastacos, G.P. (2013), "Structure and functioning of team learning emergence: a multilevel empirical validation", Journal of Management, Vol. 39 No. 6, pp. 1430-1461. doi: 10.1177/0149206311419366

Kozlowski, S.W.J. and Klein, K. J. (2000), "A multi-level approach to theory and research in organizations: Contextual, temporal, and emergent processes", in Klein, K.J. and Kozlowski, S.W.J. (Eds.), Multilevel theory, research, and methods in organizations, Jossey-Bass, San Francisco, CA, pp. 3-52.

Kozlowski, S. W. J. and Ilgen, D. R. (2006), "Enhancing the effectiveness of work groups and teams", Psychological Science in the Public Interest, Vol. 7 No. 3, pp. 77-124. doi: 10.1111/j.1529-1006.2006.00030.x

Marks, M.A., Mathieu, J.E. and Zaccaro, S.J. (2001). “A temporally based framework and taxonomy of team processes", The Academy of Management Review, Vol. 26 No. 3, pp. 356376.

Newman, I. and Benz, C.R. (1998), Qualitative-quantitative research methodology. Exploring the interactive continuum (1st ed.), Southern Illinois University, USA.

Raes, E., Kyndt, E. Decuyper, S., Van den Bossche, P., \& Dochy, F. (2015), “An exploratory study of group development and team learning", Human Resource Development Quarterly, Vol. 26, No. 1, pp. 5-30. doi:10.1002/hrdq.2120

Savelsbergh, C., van der Heijden, B.I.J.M. and Poell, R.F. (2009), “The development and empirical validation of a multidimensional measurement instrument for team learning 
behaviors", Small Group Research, Vol. 40 No. 5, pp. 578-607. doi:

$10.1177 / 1046496409340055$

Sessa, V. I. and London, M. (2008), "Group learning: An introduction", in Sessa, V.I. and London, M. (Eds.), Work group learning. Understanding, assessing and improving how groups learn in organizations, Taylor \& Francis Group, LLC New York, NY, pp. 3-13.

Sessa, V.I., London, M., Pingor, C., Gullu, B. and Patel, J. (2010), "Adaptive, generative, and transformative learning in project teams", Team Performance Management, Vol. 17 No. 3/4, pp. 146-167. doi: 10.1108/13527591111143691

Senge, M. (1990), The fifth discipline. The art \& practice of the learning organization, Doubleday, NY.

Strijbos, J.W. (2005), “A multidimensional coding scheme for VMT”, in Stahl, G. (Ed.), Studying virtual math teams, Springer, Philadelphia, USA, pp. 399-419.

Sweet, M. and Michaelsen, L. (2007), "How group dynamics research can inform the theory and practice of postsecondary small group learning", Educational Psychology Review, Vol. 19 No. 1, pp. 31-47. doi: 10.1007/s10648-006-9035-y

Uitdewilligen, S. (2011), "Team adaptation: A cognitive perspective”, Unpublished doctoral dissertation, Maastricht University, the Netherlands.

Van den Bossche, P., Gijselaers, W.H., Segers, M. and Kirschner, P.A. (2006), "Social and cognitive factors driving teamwork in collaborative learning environments: Team learning beliefs and behaviors", Small Group Research, Vol. 37 No. 5, pp. 490-521. doi:

$10.1177 / 1046496406292938$

Van der Haar, S., Wijenberg, B., Van den Bossche, P. and Segers, M. (2013), "Team Learning Behavior: A study in the setting of command and control teams", Paper presented at the 15the biennial conference Earli 2013, Munich, Germany.

Van Der Vegt, G.S. and Bunderson, J.S. (2005), "Learning and performance in multidisciplinary teams: The importance of collective team identification", Academy of Management, Vol. 48 No.3, pp. 532-547. doi: 10.2307/20159674

Veestraeten, M., Kyndt, E. and Dochy, F. (2014). Investigating team learning in a military context. Vocations and Learning, 7, 75-100. doi: 10.1007/s12186-013-9107-3 
Web, N.M. and Palinscar, A.S. (1996). "Group processes in the classroom", in Berliner, D.C. and Calee, R.C. (Eds.), Handbook of educational psychology, Macmillan, New York, NY, pp. 841-873.

West, M. (2000), "State of the art: Creativity and innovation at work", Psychologist, Vol. 13 No. 9, pp. 460 - 464. 
Appendix 1: Codes for individual verbal behaviour of team members

\begin{tabular}{|c|c|}
\hline Behaviour & Clarification \\
\hline $\begin{array}{l}\text { Structuring present team } \\
\text { meeting }\end{array}$ & $\begin{array}{l}\text { All verbal expressions that are used to clarify or structure the } \\
\text { present meeting: } 1 \text {. Indicating agenda / } 2 \text {. giving someone the } \\
\text { floor / } 3 \text {. refocusing the attention of team members to the } \\
\text { meeting / } 4 \text {. indication which agenda point has to be done later } \\
\text { in the meeting / } 4 \text {. summarize what has been done during the } \\
\text { meeting }\end{array}$ \\
\hline $\begin{array}{l}\text { Structuring future team } \\
\text { meetings }\end{array}$ & $\begin{array}{l}\text { All verbal expression that are used to structure future } \\
\text { meetings. }\end{array}$ \\
\hline Question Clarification Task & $\begin{array}{l}\text { Questions for clarification concerning the content of the task: } \\
\text { for example, 'What are we doing/going to do (work content)?'; } \\
\text { 'How are we going to do this (work method)?' }\end{array}$ \\
\hline $\begin{array}{l}\text { Question Clarification } \\
\text { Process }\end{array}$ & $\begin{array}{l}\text { Questions for clarification concerning the processes (roles and } \\
\text { procedure). For example 'How are we doing/going to arrange } \\
\text { this (work routine)?'; 'Who is doing/going to do what (division } \\
\text { of the work)?' }\end{array}$ \\
\hline $\begin{array}{l}\text { Question Clarification } \\
\text { Social }\end{array}$ & $\begin{array}{l}\text { Questions for clarification concerning personal characteristics } \\
\text { or situation of one of the team members }\end{array}$ \\
\hline Question challenge Task & $\begin{array}{l}\text { Critical question about the task with the intention to make the } \\
\text { other team members think and to generate an outcome (e.g. } \\
\text { Information, ideas or opinions) that are new for the team and } \\
\text { the individual team members. }\end{array}$ \\
\hline Question challenge Process & $\begin{array}{l}\text { Critical question about the process with the intention to make } \\
\text { the other team members think and to generate an outcome (e.g. } \\
\text { Information, ideas or opinions) that are new for the team and } \\
\text { the individual team members. }\end{array}$ \\
\hline Question challenge Social & $\begin{array}{l}\text { Critical question concerning personal characteristics or } \\
\text { situation of one of the team members with the intention to } \\
\text { make the other team members think and to generate an } \\
\text { outcome (e.g. Information, ideas or opinions) that are new for } \\
\text { the team and the individual team members. }\end{array}$ \\
\hline Affirmation Task & Agreement about task content or task method \\
\hline Affirmation Process & $\begin{array}{l}\text { Agreement about process (e.g. work routine or division of } \\
\text { work) }\end{array}$ \\
\hline Affirmation Social & Agreement about social issues \\
\hline Information simple Task & Objective information about the task \\
\hline Information simple Process & Objective information about the process \\
\hline Information simple Social & Objective information about social issues \\
\hline
\end{tabular}




\begin{tabular}{|c|c|}
\hline $\begin{array}{l}\text { Information Interpretation } \\
\text { Task }\end{array}$ & $\begin{array}{l}\text { 1. a subjective integration of information simple facts } 2 \text {. } \\
\text { interpretation or opinion concerning the task. }\end{array}$ \\
\hline $\begin{array}{l}\text { Information Interpretation } \\
\text { Process }\end{array}$ & $\begin{array}{l}\text { 1. a subjective integration of simple facts } 2 \text {. interpretation or } \\
\text { opinion concerning the process }\end{array}$ \\
\hline $\begin{array}{l}\text { Information interpretation } \\
\text { Social }\end{array}$ & $\begin{array}{l}\text { 1. a subjective integration of simple facts } 2 \text {. interpretation or } \\
\text { opinion concerning the social situation of an individual team } \\
\text { member }\end{array}$ \\
\hline $\begin{array}{l}\text { Information Anticipation } \\
\text { Task }\end{array}$ & Anticipation on future situations concerning the task \\
\hline $\begin{array}{l}\text { Information Anticipation } \\
\text { Process }\end{array}$ & Anticipation on future situations concerning the process \\
\hline $\begin{array}{l}\text { Information Anticipation } \\
\text { Social }\end{array}$ & Anticipation on future situations concerning social issues \\
\hline Command Task & Command about how to approach the task. \\
\hline Command Process & Command about how to approach the process \\
\hline Command Social & Command about how to approach social issues \\
\hline Proposal Task & $\begin{array}{l}\text { Concrete suggestions (possibly in the form of a question) } \\
\text { about the task. }\end{array}$ \\
\hline Proposal Process & $\begin{array}{l}\text { Concrete suggestions (possibly in the form of a question) } \\
\text { about the process. }\end{array}$ \\
\hline Proposal Social & $\begin{array}{l}\text { Concrete suggestions (possibly in the form of a question) } \\
\text { about the social situation of an individual. }\end{array}$ \\
\hline Decision Task & Decision that closes a topic about the task \\
\hline Decision Process & Decision that closes a topic about the process \\
\hline Decision Social & Decision that closes a topic about the social aspects \\
\hline Disagreement Task & Contrasting opinion that is given about the task \\
\hline Disagreement Process & Contrasting opinion that is given about the process \\
\hline Disagreement Social & Contrasting opinion that is given about the social situation \\
\hline
\end{tabular}


Appendix 2: items from previous research

Basic team learning behaviours.

\begin{tabular}{|l|l|l|}
\hline Sharing & Co-construction & Constructive conflict \\
\hline $\begin{array}{l}\text { In this team, I share all the } \\
\text { relevant ideas and } \\
\text { information I have }\end{array}$ & $\begin{array}{l}\text { Team members collectively } \\
\text { draw conclusions from the } \\
\text { ideas that are discussed in the } \\
\text { teams }\end{array}$ & $\begin{array}{l}\text { Comments on ideas are acted } \\
\text { upon }\end{array}$ \\
\hline $\begin{array}{l}\text { The team members listen } \\
\text { carefully to each other }\end{array}$ & $\begin{array}{l}\text { Information from team } \\
\text { members is completed with } \\
\text { information from other team } \\
\text { members }\end{array}$ & $\begin{array}{l}\text { Opinions and ideas of team } \\
\text { members are verified by } \\
\text { asking each other critical } \\
\text { questions }\end{array}$ \\
\hline $\begin{array}{l}\text { If something is unclear, we } \\
\text { ask each other questions }\end{array}$ & $\begin{array}{l}\text { Team members elaborate on } \\
\text { each other's information and } \\
\text { ideas }\end{array}$ & $\begin{array}{l}\text { This team tends to handle } \\
\text { differences of opinions by } \\
\text { addressing them directly }\end{array}$ \\
\hline
\end{tabular}

Facilitating team learning behaviours.

\begin{tabular}{|l|l|l|}
\hline Team reflexivity & Team activity & Boundary crossing \\
\hline $\begin{array}{l}\text { (Task) The team steps back } \\
\text { from daily routines to } \\
\text { consider whether the methods } \\
\text { used are the best available }\end{array}$ & $\begin{array}{l}\text { In our team, we experiment } \\
\text { with other working methods }\end{array}$ & $\begin{array}{l}\text { Team members go out and } \\
\text { get all the information they } \\
\text { possibly can from others - } \\
\text { such as costumers, or other } \\
\text { parties of the organization }\end{array}$ \\
\hline $\begin{array}{l}\text { (Task) The team often } \\
\text { reviews its objectives }\end{array}$ & $\begin{array}{l}\text { Our team tests new working } \\
\text { methods. }\end{array}$ & $\begin{array}{l}\text { This team frequently seeks } \\
\text { new information that leads us } \\
\text { to make important changes }\end{array}$ \\
\hline $\begin{array}{l}\text { (Task) The methods used by } \\
\text { the team are often discussed }\end{array}$ & $\begin{array}{l}\text { Together we plan to test new } \\
\text { working methods }\end{array}$ & $\begin{array}{l}\text { We invite people from } \\
\text { outside the team to present } \\
\text { information or have a } \\
\text { discussion with us }\end{array}$ \\
\hline $\begin{array}{l}\text { (Task) The team regularly } \\
\text { considers whether work } \\
\text { performed meets project } \\
\text { objectives }\end{array}$ & $\begin{array}{l}\text { (Task) We regularly discuss } \\
\text { whether work performed } \\
\text { meets project objectives }\end{array}$ & \\
\hline
\end{tabular}




\begin{tabular}{|l|l|}
\hline $\begin{array}{l}\text { (Process) We regularly } \\
\text { discuss whether the team is } \\
\text { working effectively together' }\end{array}$ & \\
\hline $\begin{array}{l}\text { (Process) How well we } \\
\text { communicate information is } \\
\text { often discussed }\end{array}$ & \\
\hline $\begin{array}{l}\text { (Process) The way decisions } \\
\text { are made in this team is rarely } \\
\text { altered }\end{array}$ & \\
\hline
\end{tabular}


Table 1. Examples of the different types of sharing behaviour

Type of behaviour Example

\section{Intentional information in-flow}

Information simple '....a lot of companies, higher education institutions and universities use fact that system with mentors ...'

Information

'Maybe they also copy from others...'

interpretation

Information ' '..but probably we will think of more questions at the moment itself anticipation $\ldots$

Affirmation

'Yes'

\section{Unintentional information in-flow}

Command

'You also have to keep track of the search terms you use'

Proposal

'Yes, that is something we can ask to the new people themselves...'

Decision

'Yes, that we specifically demarcate'

Disagreement

'...but budget is not only about buying train tickets'

\section{Trigger of information in-flow}

Question

'And that is only [available] in that library?'

clarification

Question challenge 'Yes, but will it be useful if they will do it like that?' 
Table 2. Different reactions to disagreement as observed in the data

\begin{tabular}{ll}
\hline Reaction to disagreement & Example (disagreement in italic) \\
\hline 1. Disagreement is ignored & TM 1: 'They already made a checklist, but it doesn't seem \\
& to work' \\
& TM 2: 'That was our checklist' \\
& TM 3: 'That [checklist] was obliged' \\
& TM 4: 'That [checklist] was obliged, mentors had to fill it \\
& out, but they didn't'
\end{tabular}

2. Disagreement is accepted

TM 1: 'I don't understand what they mean with 'professionalization of labour pedagogics'

TM 2: 'If they employ labour pedagogues, I don't know'

TM 3: 'No, what their education is'

TM 4: 'Yes, their education'

3. Disagreement leads to TM 1: 'About making a schedule: I would make it more conflicting verbal behaviours concrete' of different team members

TM 1: 'You can say: first this, then that, and then that'

TM 2: 'I would not specify yet: interviews or questionnaires'

TM 3: 'Can't we already decide whether we want to do questionnaires?'

TM4: 'I think it is a very good idea! I would really do it'

4. Disagreement leads Example 1:

constructive

behaviour

conflict TM 1: 'Imagine newcomers can come [to the group interview] and say everything they want'

TM 1: 'Yes, but I'm not sure if they will do that if other people are sitting there as well'

TM 2: 'But do we have time for that?'

TM 1: 'No no, but it would really give us a lot of information, such a group conversation with all the parties'

TM 3: 'But we can't really do all of that'

TM 4: 'Or maybe just mentors and newcomers'

TM1: 'Yes, talking to only a few of them, like in the example I just explained'

Example 2:

TM 1: 'For the reception: it seems cool to me when you have a real book, with all different possibilities to do in it or a brochure for the mentors, to make them enthusiastic'

TM 2: 'I don't think you will make them enthusiastic with a brochure'

TM 3: 'Yes, I think everything on paper is stupid'

TM 4: 'What do people like? What keeps them entertained? An I pad, a computer' 